\title{
EMERGENCY LAPAROTOMY; WITH OR WITHOUT DRAINS WHICH OPTION TO SELECT FOR PREVENTION OF DEEP SURGICAL SITE INFECTION
}

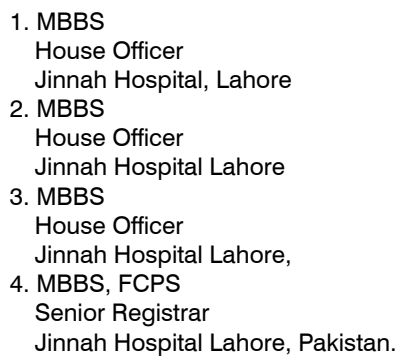

Correspondence Address:

Dr. Ch. Muhammad Atif Niaz

Doctors Hostel

Jinnah Hospital Lahore

chatif312@yahoo.com

Article received on: 23/02/2017

Accepted for publication: 29/05/2017

Received after proof reading:

05/06/2017

\section{Ch. Muhammad Atif Niaz', Awais Talib ${ }^{2}$, Yasir Sultan ${ }^{3}$, Asim Shahzad Niazi ${ }^{4}$}

ABSTRACT... Objectives: Emergency laparotomy followed by placement of drain is a common procedure in tertiary care hospitals but there are contradictory evidences regarding its association with deep surgical site infection. Thus current study was planned with an objective to compare the frequency of deep surgical site infection among patients with and without postoperative drains after undergoing an emergency laparotomy at a tertiary care hospital. Data source: Primary data based on patients undergoing emergency laparotomy at tertiary care hospital. Study design: Randomized control trial. Setting: Department of surgical unit-III, Jinnah Hospital Lahore. Duration of study: Study was conducted from January 2016 to December 2016. Subjects \& methods: About 400 patients of 15-70 years undergoing emergency laparotomy were selected using non-probability consecutive sampling technique after informed consent. Information regarding their demographic characteristics and study variable was recorded in a structured proforma. All the subjects were randomized into two groups i.e. with and without post-operative drains using table of random number. Frequency of deep surgical site infection was assessed on $7^{\text {th }}$ post operative day and data was analyzed using SPSS version 21.0. Result: The mean age of patients was $38.92 \pm 6.246$ years with about 229(57.2\%) male patients. The frequency of development of deep surgical site infection in first postoperative week was $51(12.7 \%)$ overall, with $24(12 \%)$ patients in the group of postoperative drains and $27(13.5 \%)$ patients without post-operative drains. The differences between two groups were statistically insignificant. Moreover, it was not significantly related to the age, gender, duration of stay in the hospital and smoking. Conclusion: It can be concluded from the study that there is no significantly increased risk of deep surgical site wound infection with or without placement of drain. So it is reasonable and safe approach to place a drain in the wound for the early detection of bleeding or leakage to decrease the morbidity and complication in the patients.

Keywords: $\quad$ Deep Surgical Site Infection, Emergency Laparotomy, Postoperative Drains, Peritonitis

Article Citation: Niaz CMA, Talib A, Sultan Y, Niazi AS. Emergency laparotomy; With or without drains; which option to select for prevention of deep surgical site infection. Professional Med J 2017;24(6):808-811. DOI: 10.17957/TPMJ/17.4075

\section{INTRODUCTION}

Health care associated infections are a significant cause of mortality and financial losses for health system affecting developing and developed countries equally world-wide. Among the HAI, Surgical site infection (SSI) is the most frequent type in developing countries with a pooled incidence of 11.8 per 100 surgical procedures (range 1.2 to 23.6). ${ }^{1}$ Even in developed countries like Europe and United States of America, it is the second most frequent type of HAl. ${ }^{2}$ Various studies in Pakistan reported SSI ranging from $6.5 \%$ to $13 \%$ depending upon the type of wound and set up of surgery. ${ }^{3-5}$
The dictum of Lawson Tait, "When in doubt, drain", is a common practice of surgeons worldwide in all surgical procedures. It helps the surgeon not only to detect anastomosis leakage early but also reduce postoperative adhesions. But on the other hand, the controversy in the data raises a question mark on its usage as it is argued that it might cause adverse surgical outcome by causing infection in the anastomotic area and the abdominal wound affecting anastomotic healing. ${ }^{6}$ Talving $P$ reported a significantly higher incidence of SSI among patients with drain placement $31 \%$ as compared to $9 \%$ in patients without drains. ${ }^{7}$ But Mohseni et al. found a statistically 
insignificant difference with SSI developing in $17 \%$ and $18 \%$ of patients with drain and without drain respectively. ${ }^{8}$ Another retrospective review to determine safety and effectiveness of routine drainage and nondrainage also reported no significant difference in the rate of surgical site infection or mean length of hospital stay. ${ }^{9}$

Thus current study was an attempt to generate further evidence to help surgeons choosing a better practice regarding the placement of drains in term of lower rate of deep surgical site infection. DSSI is a common cause of increased morbidity and prolonged hospital stay. Thus evidence based management of post surgical patients for the prevention of deep surgical site infection will help in achievement of early restoration of health, decreased morbidity and length of stay in hospital along with a reduction in bed occupancy rate thus leading to decreased patient burden on already resource depleted health system of countries like Pakistan.

\section{METHODOLOGY}

This was a randomized control trial conducted in department of surgical unit-III, Jinnah Hospital Lahore during January 2016 to December 2016. After approval from Ethical Review Committee, about 400 patients presenting to surgical emergency with diagnosis of peritonitis were evaluated by consultant. Patients fulfilling the selection criteria were included in the study after taking an informed consent using non-probability consecutive sampling technique. Patients with suspected pancreatitis, diabetics, chronic liver disease, Immune compromised, or having history of hypersensitivity reactions or known allergy to latex or drain material were excluded from the study. All the patients were randomly divided into two groups by using random number table i.e. with and without placement of drains.

All the operations were given preoperative treatment using standard protocol and all the emergency laparotomies were carried out by same consultant under general anesthesia. Patients were followed post operatively during the first post-operative week for presence of deep surgical site which was defined as clinical picture of infection (fever $>102^{\circ} \mathrm{F}$, abdominal tenderness on palpation) and presence of intra-abdominal abscess or collection on ultrasonography. Data was collected on a structured proforma containing variables of interest like age, sex, Presence of DSSI, type of surgery, treatment group. Current history of smoking and length of hospital stay was recorded additionally as effect modifier.

All the data from the proforma was entered and analyzed in the SPSS version 21.0. The descriptive statistics like age were presented in the form of mean and standard deviation while smoking and presence of deep surgical site infection as frequency and percentage. Chi square test of homogeneity was applied to determine statistical difference in both groups regarding rate of DSSI during the first postoperative week. A value of $p$ $<0.05$ was considered as statistically significant.

\section{RESULTS}

About 400 patients were included in the study having mean age of $38.92 \pm 6.246$ years and 229 (57.2\%) male patients. Overall, about 51 (12.7\%) patients developed surgical site wound infection during the first post-operative week. Among the two groups i.e. with drain and without drains, deep surgical site infection was seen in $24(12 \%)$ patients with post-operative drains and in 27 (13.5\%) patients without post-operative drains (Table I). The difference between the two groups after application of chi-square test was statistically insignificant $(p=0.32)$. On stratification of the data with respect to age, gender, smoking and duration of stay in the hospital none was found to be significantly related with deep surgical site infection. (Table-II).

\section{DISCUSSION}

Surgical site infections are common health care associated complications and always a challenge for surgeons leading to drastically escalated morbidity and mortality along with jeopardized health outcomes. Accordingly, the concept of "Clean care is safer care" is vital in the prevention of SSI and comprises of all meticulous effort to prevent the development of SSI. However, 


\begin{tabular}{|c|c|c|c|c|c|c|}
\hline & & \multicolumn{4}{|c|}{ Deep Surgical Site Infection } & \multirow{3}{*}{$\begin{array}{l}\text { Total } \\
200\end{array}$} \\
\hline & & \multirow{2}{*}{\multicolumn{2}{|c|}{$\begin{array}{c}\text { Yes } \\
24(12 \%)\end{array}$}} & \multicolumn{2}{|l|}{ No } & \\
\hline \multirow{2}{*}{ group } & With drain & & & \multicolumn{2}{|l|}{176 (88\%) } & \\
\hline & Without drain & \multicolumn{2}{|l|}{$27(13.5 \%)$} & $173(86.5 \%)$ & & 200 \\
\hline \multicolumn{2}{|r|}{ Total } & $51(12.7 \%)$ & & $349(87.3 \%)$ & & 400 \\
\hline \multicolumn{7}{|c|}{$\begin{array}{c}\text { Table I. development of deep surgical site infection with and without drain } \\
\text { Using chi square test, } p \text { value }=0.32 \text { (insignificant) }\end{array}$} \\
\hline \multirow{2}{*}{\multicolumn{3}{|c|}{ Effect modifier }} & \multicolumn{2}{|c|}{ Deep Surgical Site Infection } & \multirow{2}{*}{ Total } & \multirow[b]{2}{*}{$P$ value } \\
\hline & & & yes & no & & \\
\hline \multirow{2}{*}{\multicolumn{2}{|c|}{ Age }} & $<35$ years & 23 & 151 & 174 & \multirow{2}{*}{0.40} \\
\hline & & $>35$ years & 28 & 198 & 226 & \\
\hline \multirow{2}{*}{\multicolumn{2}{|c|}{ Sex }} & Male & 27 & 202 & 229 & \multirow{2}{*}{0.25} \\
\hline & & Female & 24 & 147 & 171 & \\
\hline \multirow{2}{*}{\multicolumn{2}{|c|}{ Smoking }} & Smoker & 30 & 211 & 241 & \multirow{2}{*}{0.41} \\
\hline & & Non-smoker & 21 & 138 & 159 & \\
\hline \multirow{2}{*}{\multicolumn{2}{|c|}{ Duration of hospital stay }} & Less than 5 days & 25 & 163 & 188 & \multirow{2}{*}{0.37} \\
\hline & & 5 days or more & 26 & 186 & 212 & \\
\hline
\end{tabular}

Table-II. Stratification for effect modifiers for the development of SSI

in this regard the role of drains is controversial due to inconsistencies in the existing literature. Thus this study was aimed for providing further insight regarding the role of postoperative drains in development of SSI so that the results can be used to generate evidence based guidelines for the surgeons to distinguish them clearly as friend or foe.

About 400 patients were enrolled in this trial and were divided into two groups i.e. one with placement of drain and the other without drains. The results of this study showed that overall frequency of development of SSI was $12.7 \%$ which is quite similar to the previous study conducted by Malik et al. in Pakistan. ${ }^{5}$ Moreover, it was seen that there is no statistically significant difference in the development of SSI with and without drain. These results are also consistent with findings of Mohseni et al. ${ }^{8}$ who are reported similar observation. This fact highlights that drains can be used safely in patients undergoing laparotomy without any additional risk of SSI. However, Talving et al. ${ }^{7}$ reported different results with a significant increase in the SSI in group with placement of drain as compared to without drain. This difference can be attributed due to a smaller sample size of that study along with the difference in characteristic of wound injury, operative conditions and postoperative care of the wound depending on the setup.

Another noteworthy finding of this study is that age, gender, smoking and duration of stay in hospital were found to play no significant role in the development of SSI along with drain placement. This highlights the fact that drains placement can be done in any age group or gender to be on the safer side for early detection of the leakage.

WHO developed guidelines for the prevention of development of SSI based on the available literature. ${ }^{10}$ It was seen that some low quality evidence is available regarding the use of prolonged antibiotic prophylaxis in patients with placement of drain. It was seen that prolong use of antibiotic in presence of a wound drain has neither benefit nor harm in reducing SSI when compared to per operative prophylaxis alone (OR: 0.79 ; $95 \% \mathrm{Cl}$ : $0.53-1.20) .{ }^{10}$ Considering the lack of evidence that prolonged antibiotic prophylaxis prevents SSI and the possible associated side effects of antibiotics, the WHO expert panel unanimously agreed that antibiotic prophylaxis should not be continued in the presence of a wound drain. Similarly regarding the removal of drain, very low quality evidence shows that the early removal of wound drains has neither benefit nor harm in reducing the SSI rate when compared to late removal of drains (at postoperative day 6 or 
later). Results were also similar when comparing early removal with removal determined according to the volume of drainage. Considering the very low quality evidence and the finding that the body of evidence does not identify an optimal time point for wound drain removal with regard to the prevention of SSI, the expert committee suggested that the wound drain should be removed when clinically indicated. ${ }^{10}$

Thus the available evidence clearly suggests that drain can be used safely in the surgery and can play a role of friend for the surgeons for early detection of any leakage or fluid accumulation so that immediate step can be taken to rectify the condition.

\section{CONCLUSION}

It can be concluded from the study that placement of drain is a safe approach with no increased risk of development of SSI. Moreover, it neither requires prolonged use of antibiotics nor its late removal is associated with any additional risk posing harm to patients. Thus the benefit of use of drain as a secondary preventive measure for early detection of anastomotic leakage and immediate management is an evidence based practice and should be adopted by surgeons whenever they are doubtful to decrease the leakage related complications of the surgery leading to early recovery and decreased bed occupancy rate with improved outcomes on the health of patients and weaving off financial burden on already overburdened health system of the country.

\section{Copyright $\odot$}

\section{REFERENCES}

1. Allegranzi B, Bagheri Nejad S, Combescure C, Graafmans W, Attar H, Donaldson L, et al. Burden of endemic health-care-associated infection in developing countries: systematic review and metaanalysis. Lancet. 2011;377(9761):228-41.

2. Report on the burden of endemic health careassociated infection worldwide. A systematic review of the literature. Geneva: World Health Organization; 2011.

3. Sangrasi AK . Surgical site infection rate and associated risk factors in elective general surgery at a public sector medical university in Pakistan. International Wound Journal 2008;5(1):74-78.

4. Khan M, Khalil J, Zarin M, Hassan TU, Ahmed N, Salman $M$, et al. Rate and risk factors for surgical site infection at a tertiary care facility in Peshawar, Pakistan. $J$ Ayub Med Coll Abbottabad. 2011 Mar 1;23(1):15-8.

5. Malik AZ, Ali Q. Surgical Site Infections after Elective Surgery in Pakistan: SURGIPAK Study. JRMC 2015;19(3):209-14.

6. Allegranzi B, Zayed B, Bischoff P, Kubilay NZ, de Jonge $S$, de Vries F, et al. New WHO recommendations on intraoperative and postoperative measures for surgical site infection prevention: an evidence-based global perspective. The Lancet Infectious Diseases. 2016 Dec 31;16(12):e288-303.

7. Talving P, Mohseni S, Inaba K, Plurad D, Branco BC, Lam L, Chan LS, Demetriades D. Closed suction drain after isolated hollow viscus injury: a friend or foe? $\mathrm{J}$ Trauma 2011;70(6):1424-8.

8. Mohseni S, Talving P, Kobayashi L, Kim D, Inaba K, Lam L, Chan LS, Coimbra R, Demetriades D. Closed-suction drain placement at laparotomy in isolated solid organ injury is not associated with decreased risk of deep surgical site infection. Am Surg 2012;78(10):1187-91.

9. Nasir AA, Abdur-Rahman LO, Adeniran JO. Is intraabdominal drainage necessary after laparotomy for typhoid intestinal perforation? J Pediatr Surg 2012;47(2):355-8.

10. World health organization. Global Guidelines for the Prevention of Surgical Site Infection. 2016. Available at: http://apps.who.int/iris/bitstre am/10665/250680/1/9789241549882-eng.pdf

\section{AUTHORSHIP AND CONTRIBUTION DECLARATION}

\begin{tabular}{|c|c|c|c|}
\hline Sr. \# & Author-s Full Name & Contribution to the paper & Author $=\mathbf{s}$ Signature \\
\hline 1 & Dr. Ch. Muhammad Atif Niaz & $\begin{array}{l}\text { Data collection, Analysis, } \\
\text { Interpretation }\end{array}$ & \\
\hline 2 & Dr. Awais Talib & $\begin{array}{l}\text { Data compilation, } \\
\text { Referecnes }\end{array}$ & Anesis \\
\hline 3 & Dr. Yasir Sultan & Data compilation, Proof & \\
\hline 4 & Dr. Asim Shahzad Niazi & $\begin{array}{l}\text { readıng } \\
\text { Proof reading, Typing }\end{array}$ & $\operatorname{tag} s$ \\
\hline
\end{tabular}

